\title{
Sajedeen $M^{1}$ BDS, FCPS, Rizvi H $M^{2}$ BDS and Hossain M Z ${ }^{3}$ BDS, PhD.
}

\begin{abstract}
:
Class III malocclusions are considered one of the most complex and difficult orthodontic problems to diagnose and treat. Skeletal and/or dental asymmetries in patients presenting with Class III malocclusions can worsen the prognosis. Recognizing the dentoalveolar and skeletal characteristics of Class III malocclusions and their treatment possibilities is essential for a favorable nonsurgical correction. Therefore, this article presents a nonsurgical extraction approach to Class III malocclusion treatment which can significantly improve the occlusal and facial discrepancies.
\end{abstract}

Key words: Class III malocclusion, Extraction, Midline deviation, Nonsurgical treatment (Ban J Orthod and Dentofac Orthop, Oct 2011; Vol-2, No. 1, p 20-25)

\section{INTRODUCTION:}

The Skeletal Class III malocclusion is characterized by mandibular prognathism, maxillary deficiency or both. ${ }^{1-3}$ Clinically, these patients exhibit a concave facial profile, a retrusive nasomaxillary area and a prominent lower third of the face. The lower lip is often protruded relative to the upper lip. The upper arch is usually narrower than the lower, and the overjet and overbite can range from reduced to reverse. ${ }^{4}$

The effect of environmental factors and oral function on the etiological factors of a Class III malocclusion is not completely understood. However, there is a definite familial and racial tendency to mandibular prognathism. 5,6

For many Class III malocclusions, surgical treatment can be the best alternative. Depending on the amount of skeletal discrepancy, surgical correction may consist of mandibular setback, maxillary advancement or a combination of mandibular and maxillary procedures. After surgical correction of the skeletal discrepancy, the occlusion is usually finished orthodontically to a Class I relationship. However, if surgical treatment is not performed, and the final molar relationship is Class III or Class I, there are challenges specific to the static and functional Class III occlusion that must be considered. ${ }^{7}$

Sometimes a Class III relationship is caused by a forward shift of the mandible to avoid incisal interferences. This is a pseudoClass III malocclusion. In these cases, it is important to establish the inter-occlusal relationship with the teeth in the retruded contact position. ${ }^{8}$ In this paper, the non-surgical orthodontic treatment of one patient with a Class III malocclusion is discussed .

\section{CASE REPORT}

\section{Patient history}

A 11-year-old female from Potuakhali Barisal reported to DDCH with the complaints of unpleasant aesthetic look due to

prominence of chin as well as complaints of difficulty to bite on $31^{\text {st }}$ Aug 2005. She presented with a severe dental and skeletal Class III malocclusion. The patient's profile was concave (Figure $1)$.

The lower lip was prominent and lips were competent with no mentalis strain. Vertical facial proportions showed increased lower facial height and there were no significant asymmetries. A full complement of permanent teeth were present except for upper (18 and 28) and lower right (48) 3rd molar teeth germs.(fig 3)

In both centric occlusion $(\mathrm{CO})$ and centric relation $(\mathrm{CR})$ molar and canine relationships were Class III, and the incisors had an anterior crossbite with a negative overjet of $3 \mathrm{~mm}$. Posterior crossbite was also present (Fig 2).

The curve of Spee was moderate with a $3 \mathrm{~mm}$ overbite in both $\mathrm{CO}$ and CR. The Maxillary arches exhibited moderate arch length discrepancies with crowding. Oral hygiene was moderate. The pre-treatment cephalometric evaluation (Figure 4 and Table 1) showed that: Severe anteroposterior skeletal jaw dysplasia. Attributed mainly to a prognathic mandible. Upper incisors are tipped forward relative to skeletal pattern. Mandibular plane angle appears normal.

\section{Fig 1 Pre treatment extra oral photographs}

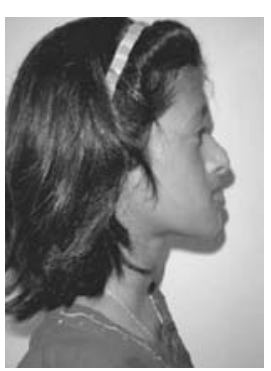

Right profile view

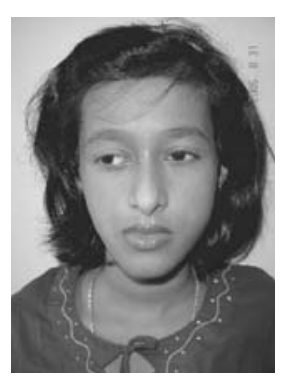

Frontal view

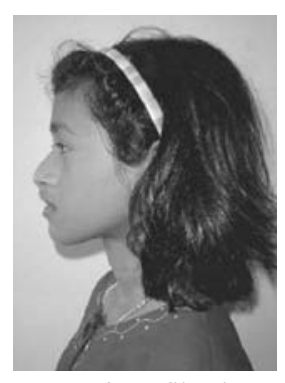

Left profile view

${ }^{1}$ Asstt Prof. Dept. of Orthodontics; DDCH. ${ }^{2}$ FCPS Trainee, Dept. of Orthodontics DDCH. ${ }^{3}$ Prof. and Head, Department of Orthodontics, DDCH. 
Fig 2 Pre treatment Intra oral photographs
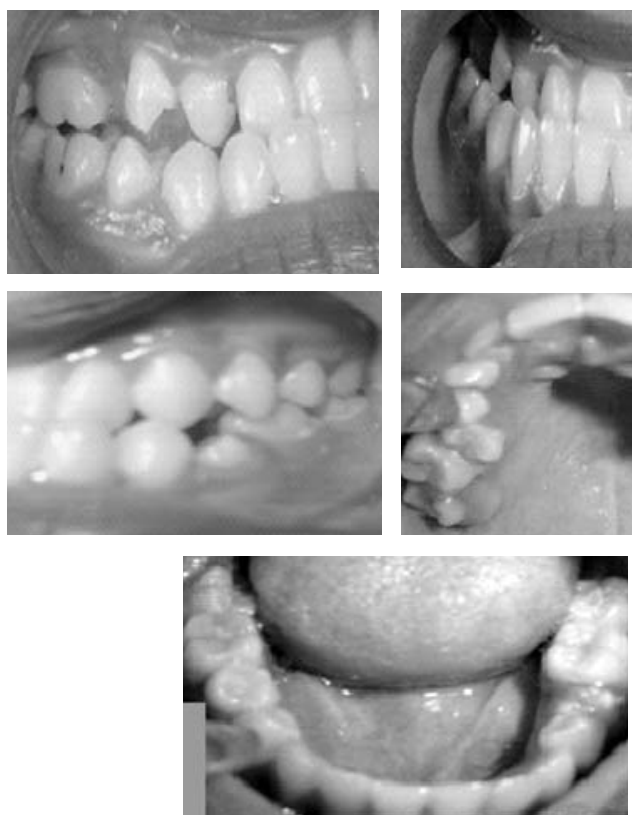

Fig 3 Pre treatment OPG

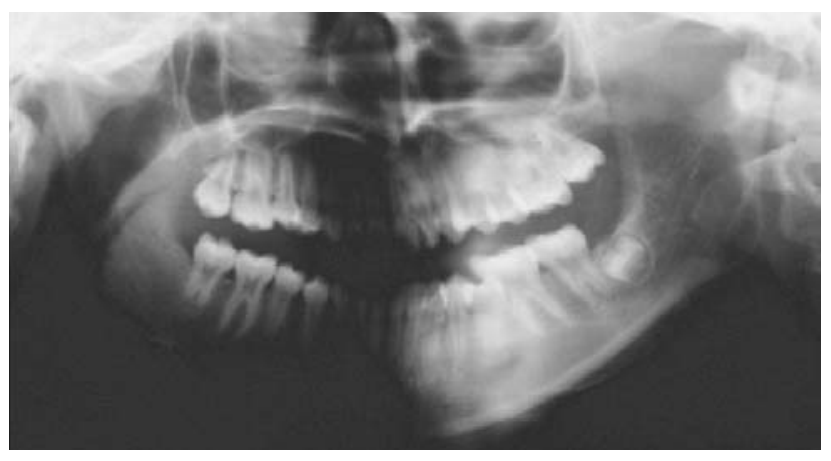

\begin{tabular}{lll}
\hline Parameter & $\begin{array}{l}\text { Reference } \\
\text { Measurement }\end{array}$ & $\begin{array}{l}\text { Patient's } \\
\text { Measurement }\end{array}$ \\
\hline SNA (angle) & $82^{\circ}$ & $80^{\circ}$ \\
SNB (angle) & $80^{\circ}$ & $87^{\circ}$ \\
ANB (angle) & $2^{\circ}$ & $-7^{\circ}$ \\
U1 to NA (mm) & $4 \mathrm{~mm}$ & $8 \mathrm{~mm}$ \\
U1 to NA (angle) & $22^{\circ}$ & $34^{\circ}$ \\
L1 to NB (mm) & $4 \mathrm{~mm}$ & $4 \mathrm{~mm}$ \\
L1 to NB (angle) & $25^{\circ}$ & $20^{\circ}$ \\
Inter incisal angle & $131^{\circ}$ & $130^{\circ}$ \\
U1 max plane & $108^{\circ}$ & $123^{\circ}$ \\
L1 mand plane & $92^{\circ}$ & $83^{\circ}$ \\
Go Gn to SN (angle) & $32^{\circ}$ & $33^{\circ}$ \\
Occlu to SN (angle) & $14^{\circ}$ & $12^{\circ}$ \\
\hline
\end{tabular}

Cephalometry reveals severe anteroposterior skeletal jaw dysplasia. Attributed mainly to a prognathic mandible. Upper incisors are tipped forward relative to skeletal pattern. Mandibular plane angle appears normal.
Fig 4 Pre treatment Lateral cephalometric tracing
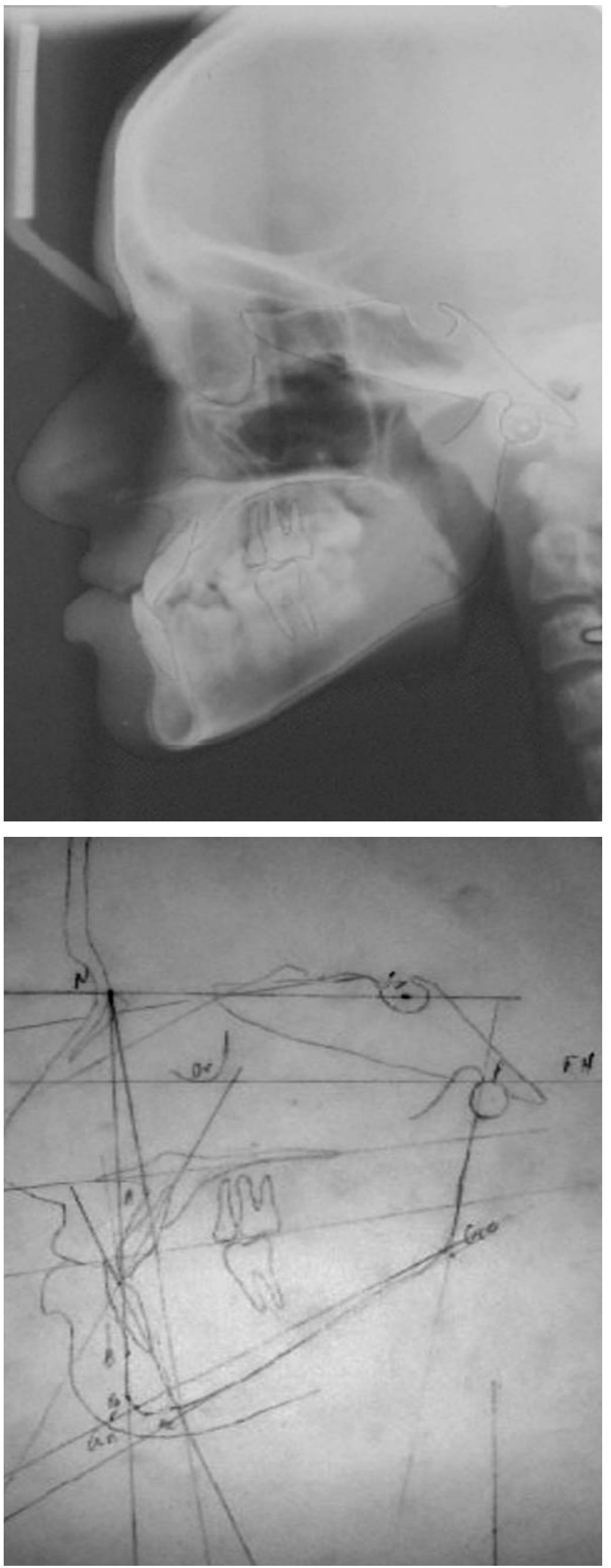


\section{DIAGNOSIS :}

A case of class III malocclusion with anterior cross bite and crowding in the upper arch.

\section{TREATMENT OBJECTIVES}

1. To eliminate anterior and posterior crossbite;

2. To establish Class I canine relationships;

3. To eliminate maxillary arch length discrepancy;

4. To align the arches;

5. To correct the overbite, overjet and midlines;

6. To provide an aesthetic smile.

\section{TREATMENT PLAN}

\section{1st phase}

Correction of class III jaw relationship by class III activator. (adding acrylic resin to the activator at monthly consecutive visits to advance the upper jaw forward) ( Fig 5,6)

\section{2nd phase}

Mandibular 1st premolars were extracted. Maxillary and mandibular fixed appliances (standard edgewise 0.018-inch) were used. After initial leveling and alignment with .014 inch round multiloop arch wires in both the upper and lower dental arches, a $0.016 \mathrm{X} 0.022$-inch ss utility arch was used for protrusion of the upper incisors. For retrusion of the mandibular incisors 0.016X022-inch contraction arch combined with Class III elastics was used. Fixed appliance treatment was completed in 26 months.(Fig 8)

Fig 5 Class III activator to correct jaw discrepancy

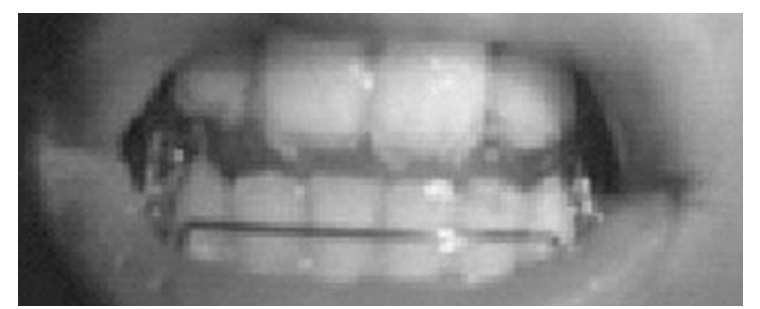

Correction of class III jaw relationship by class III activator (adding acrylic resin to the activator at monthly consecutive visits to advance the upper jaw forward).

Fig 6 Results of six months of Class III activator use

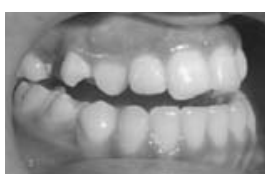

Right buccal view

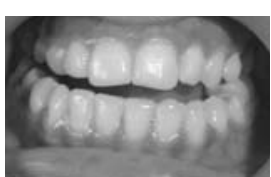

Frontal view

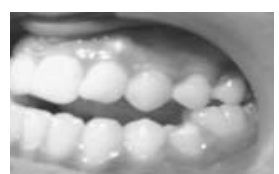

Left buccal view

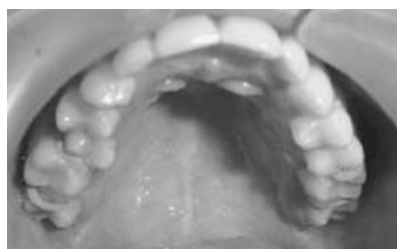

Occlusal view upper

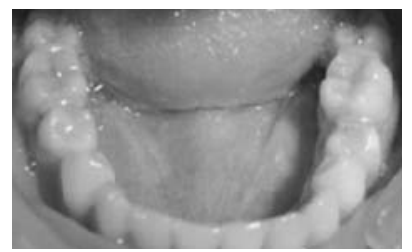

Occlusal view lower
Fig 7: Pre and post treatment cephalometric $\mathrm{x}$ rays

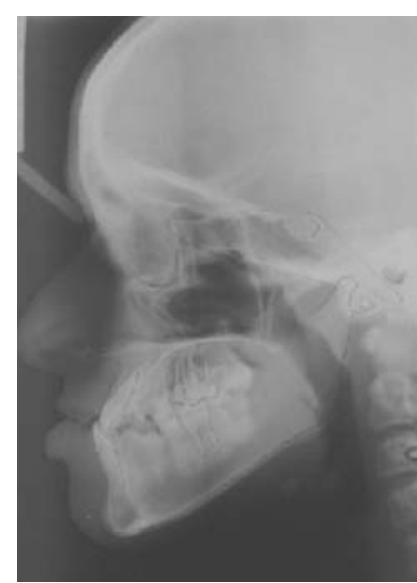

Pre treatment Cephalogram

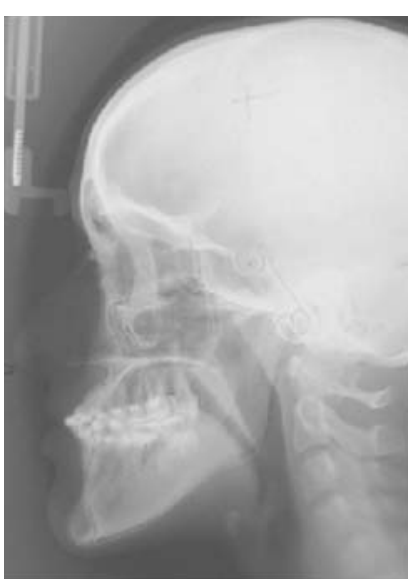

Post treatment Cephalogram
Fig 8: Treatment sequence in 2nd stage of treatment
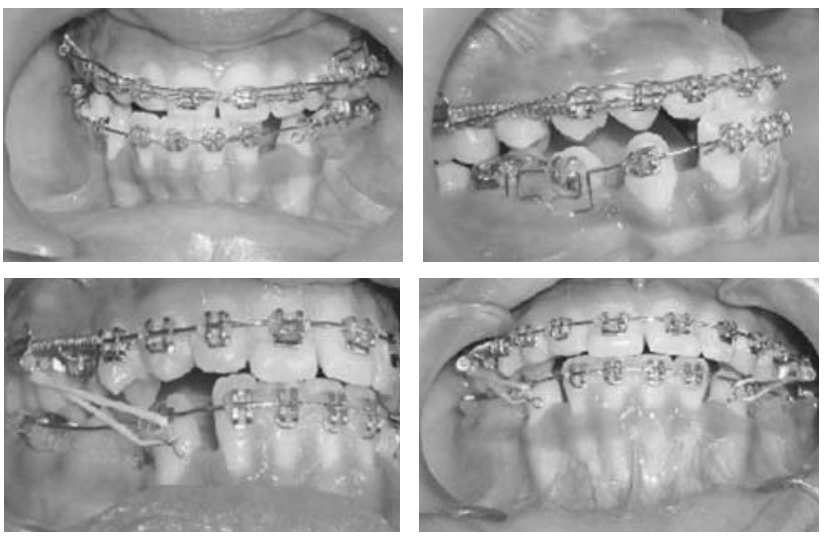

\section{TREATMENT RESULTS}

The treatment plan was a satisfactory non-surgical alternative, and the treatment objectives were achieved (Figures 7-10). Class I canine relationships were established with good alignment of the teeth. Some occlusal adjustment was needed to finalize the occlusion. A positive overjet was established and the overbite was somewhat reduced. Good torque control was maintained while the mandibular incisors were retracted resulting in better incisal inclination after treatment. The maxillary incisors were proclined significantly resulting in better upper lip prominence and an improved facial profile. Correction of the malocclusion was accomplished with dental movement. Skeletally, the mandible was still prognathic, and the chin was slightly prominent. 
Fig 9: Pre and post treatment intra oral photographs

Before treatment
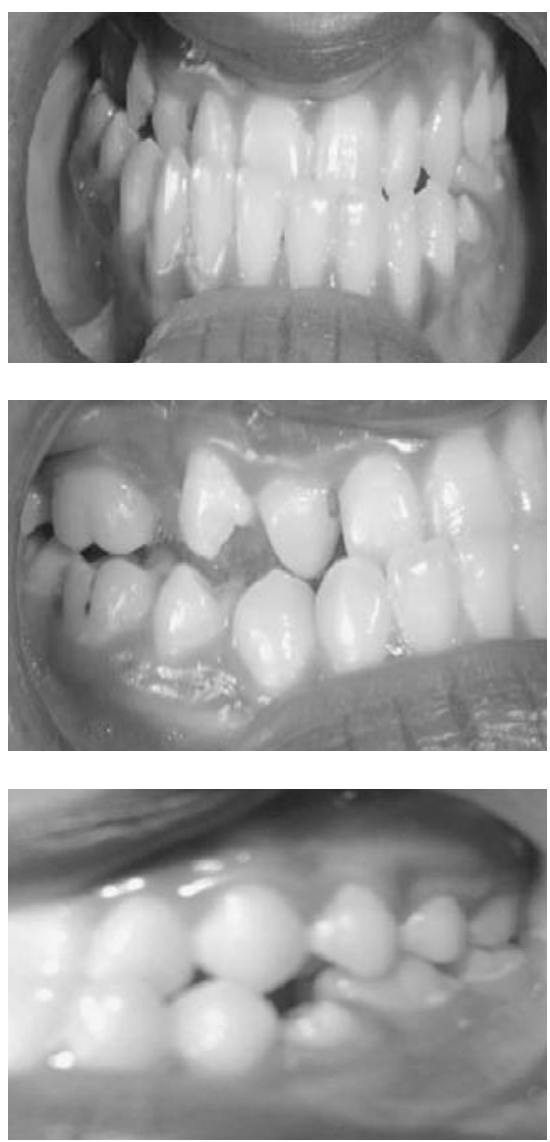

After Myofunctional treatment
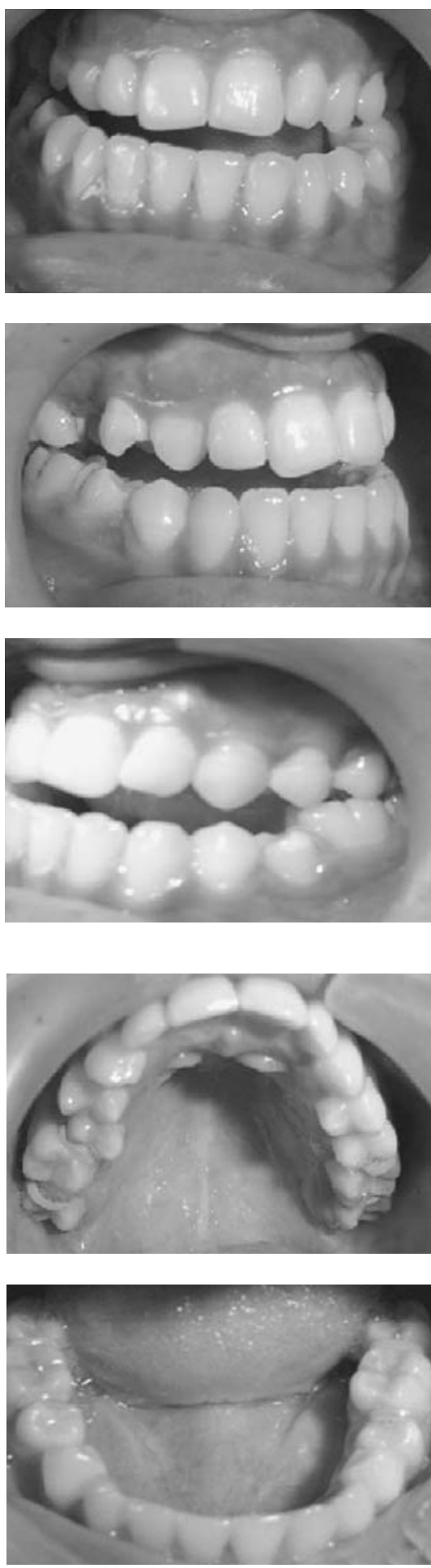

Final stage
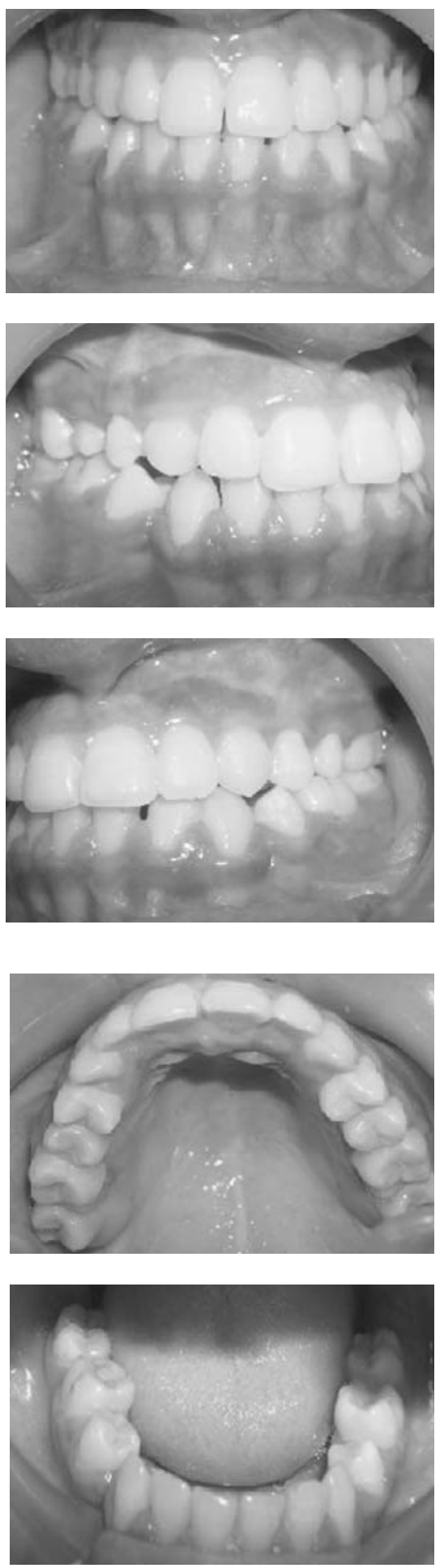
Fig 10: Pre and post treatment extra oral photographs

Before treatment
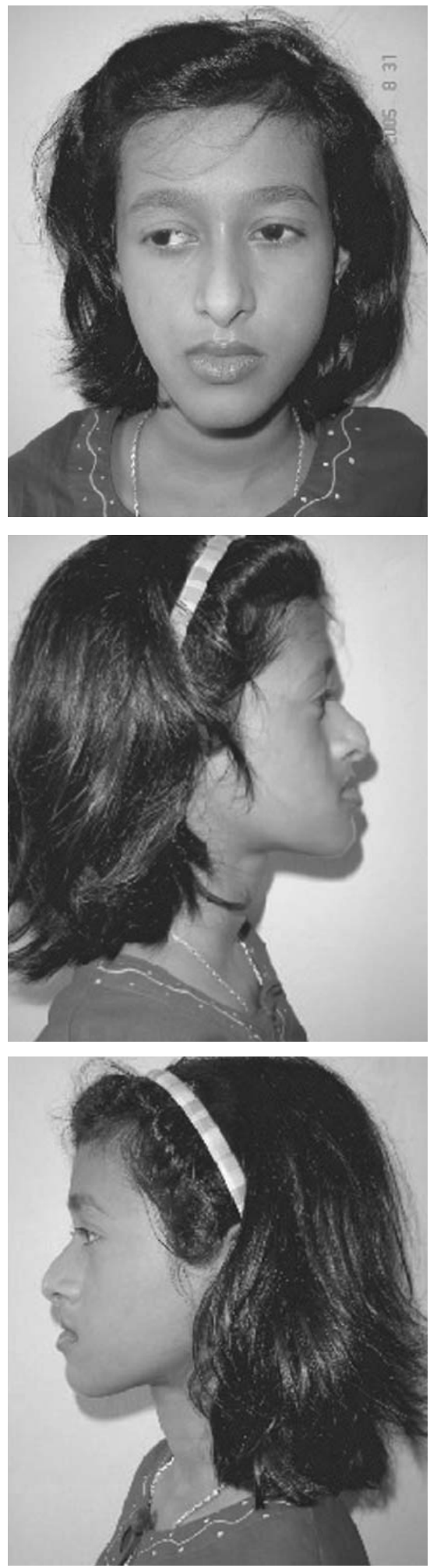

After Myofunctional treatment
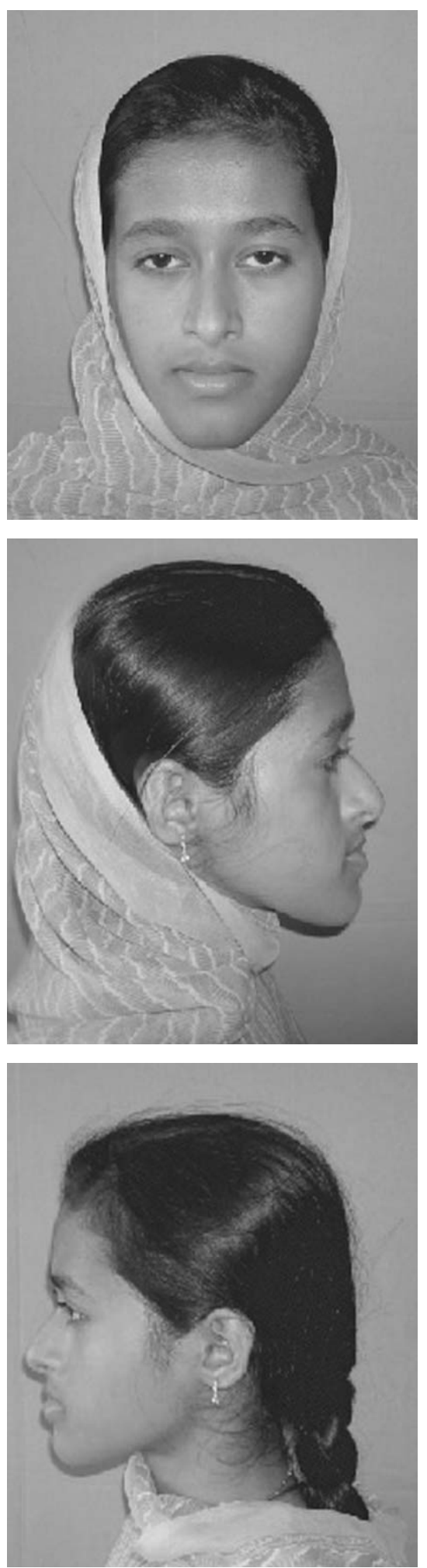

Final stage
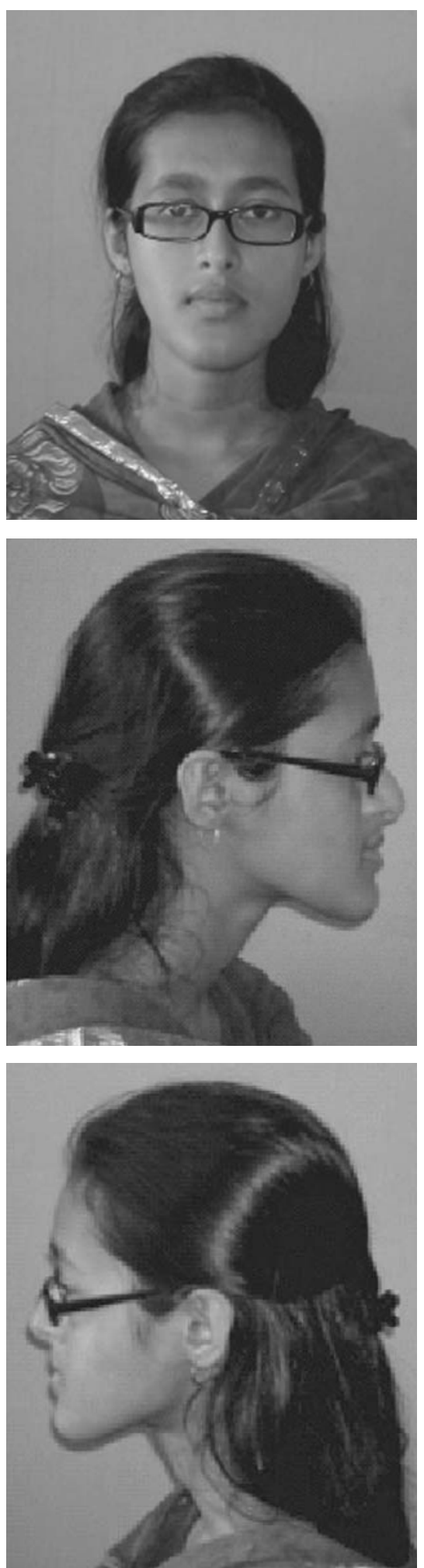


\section{DISCUSSION}

The surgical correction of Class III malocclusion can be undertaken in a variety of ways, e.g. a bilateral sagittal split osteotomy to retract the mandible or a Le Fort I procedure to advance the maxilla, or a combination of these. However, the associated surgical risks and complications must be considered, as well as the increased expense. ${ }^{7}$ If a non-surgical treatment alternative can produce results comparable with those that could be achieved surgically, then it should be considered and can be the treatment of choice for some patients.

Palatally inclined maxillary incisors can be moved labially and labially inclined mandibular incisors can be moved linguallyeven to overcorrected positions-to establish a normal overjet. ${ }^{1}$ It was believed that acceptable facial profiles and functional occlusions could be achieved by treating this patient with protrusion of upper incisors and retrusion of lower incisors using fixed appliances without the need for orthognathic surgery. At the end of treatment, the chin of the patient was prominent. But it was acceptable by the patient. Class III elastics were used after initial leveling and alignment with round arch wires in both arches to retract the lower incisors and aid maxillary posterior anchorage during protrusion of the upper incisors. The retraction of the lower incisors allowed for the establishment of a Class I canine relationship. The molars were left in a Class III relationship.The utility arch was very useful to protrude the upper incisors. If necessary a utility arch can be used to extrude the incisors.

The functional excursions are not usually a problem because Class I canines and good overbite/overjet relations are established. Incisal and canine guidance can be achieved. Group function in lateral excursions can also be achieved but is more difficult because of the molar/premolar occlusion. In addition to retraction of the mandibular anteriors some proclination of the maxillary incisors is usually required to establish good overjet relations. This proclination can also add prominence to the upper lip, and produce a better aesthetic relationship between the upper and lower lips. A sufficient overbite can actually help retain the correction of an anterior crossbite. If such a patient has zero or a negative overbite, the incisors will be prone to relapse after being moved into position.

\section{CONCLUSION:}

This paper presents the non-surgical orthodontic treatment of an adult patient presenting with Class III malocclusions. Treatment was undertaken using a combination of compensation mechanics and fixed orthodontic appliance treatment only and suggests that in some, carefully selected cases, this approach can be a viable treatment option.

\section{REFERENCES}

1. Sanborn RT. Differences between the facial skeletal patterns of Class III malocclusion and normal occlusion. Angle Orthod 1955; 25: 20822.

2. Guyer EC, Ellis EE, McNamara JA Jr, Behrents RG.Components of Class III malocclusion in juveniles and adolescents. Angle Orthod 1986; 56: 7-30.

3. Williams S, Andersen CE. The morphology of the potential Class III skeletal pattern in the growing child. Am J Orthod Dentofac Orthop 1986; 89: 302-11.

4. Ngan P, Hagg U, Yiu C, Merwin D, Wei SHY. Soft tissue and dentoskeletal profile changes associated with maxillary expansion and protraction headgear treatment.Am J Orthod Dentofac Orthop 1996; 109: 38-49.

5. Litton SF, Ackerman LV, Isaacson RJ, Shapiro B. A genetic study of Class III malocclusion. Am J Orthod 1970;58: 565-77.

6. Mossey PA, The heritability of malocclusion: Part 2. The influence of genetics in malocclusion. Br J Orthod 1999; 26:195-203.

7. Popp TW, Gooris CGM, Schur AJ. Nonsurgical treatment for a Class III dental relationship: a case report Am J Orthod Dentofac Orthop 1993; 103: 203-11.

8. Clark JR, Hutchinson I, Sandy JR. Functional occlusion:II. The role of articulators in orthodontics. J Orthod 2001;28: 173-7.

\section{Correspondence :}

\section{Dr. Hasan Md. Rizvi, BDS}

FCPS (Orthodontics)

Dept. of Orthodontics and Dentofacial Orthopedics

Dhaka dental College and Hospital

Mirpur 14, Dhaka 1206

Mobile : +8801710918222, E-mail : hasanriz2008@yahoo.com 